Int. J. Odontostomat., 11(4):467-473, 2017.

\title{
Influence of Surface Sealants on Microleakage in Composite Restorations
}

\author{
Estudio de la Influencia de los Sellantes de Superficie \\ sobre la Microfiltración en Restauraciones de Composite
}

Urquía Morales C.; Brasca N.; Girardi M.; Bonnin C.; Ríos A.; Girardi I.; Chávez Lozada J. \& Delgado, A.

URQUÍA, M. C.; BRASCA, N.; GIRARDI, M.; BONNIN, C.; RÍOS, A.; GIRARDI, I.; CHÁVEZ, L. J. \& DELGADO, A. Influence of surface sealants on microleakage in composite restorations. Int. J. Odontostomat., 11(4):467-473, 2017.

\begin{abstract}
Polymerization shrinkage of composites can generate stress that results in the formation of microgaps at the resin-enamel interface and marginal leakage. The aim of the present work was to evaluate the influence of surface sealants on microleakage in composite restorations. Enamel-dentin occlusal cavities were prepared in 30 non-carious upper and lower premolars. The cavities were restored with One Coat Bond SL and Brilliant New Generation (Coletene), following the manufacturers' instructions, and polished appropriately. The samples were randomly assigned to one of the following six treatment groups: Group I (Control-no sealant); Group II: Single Bond (3M/ESPE); Group III: Perma Seal (Ultradent); Group IV: Heliobond (Vivadent); Group V: Biscover LV (Bisco); Group VI: Bioforty (Biodinâmica). The samples were then immersed in $2 \%$ aqueous methylene blue solution for 48 hours, and thermocycled 100 times from $5{ }^{\circ} \mathrm{C}$ to $55^{\circ} \mathrm{C}$. The obtained specimens were ground in a bucco-palatal orientation to reach the medial plane, and observed under a stereoscopic loupe at 40X. The degree of microleakage was evaluated by assessing the penetration of the dye to the tooth-restoration interface, using a 0 to 3 grading scale. The obtained data were analyzed using the Kruskal-Wallis non-parametric test. Significant differences were observed between all rebonded groups and the control group; no differences were observed among Single Bond, Perma Seal and bioforty, or between Heliobond and Biscover LV. It would seem convenient to apply a surface sealant over composite restorations to improve marginal integrity and reduce microleakage.
\end{abstract}

KEY WORDS: microleakage, surface sealants, composites.

\section{INTRODUCTION}

Composite resins are widely used as restoration materials in dentistry, owing to esthetic demands of patients and to the ability of these materials to bond to the tooth structure and allow for more conservative cavity preparations (Stein et al., 2005; Silva Santana et al., 2009). New formulations of composite resins are continuously being introduced with the aim of improving their physical and mechanical properties (Zimmerli et al., 2010). This is achieved by decreasing the size, shape and distribution of inorganic filler particles, and increasing their radiopacity. One of the most important discoveries in recent years is the application of nanotechnology to the manufacture of composite resins. Using nanotechnology allows manufacturers to provide highly filled composite resins, with higher wear resistance and better polishability and gloss. The greatest limitation to composite resins seems to be polymerization shrinkage. Shrinkage means densification or volume loss. The formation of macromolecules during light curing is associated with the shrinkage of the organic material that is being polymerized; hence intermolecular distance (Van Der Waals distance) of a monomer ranges from $0.3 \mathrm{~nm}$ to $0.4 \mathrm{~nm}$. When the material polymerizes, a $0.15 \mathrm{~nm}$ long covalent bond forms, resulting in a $2 \%$ decrease in intermolecular distance. This volumetric contraction of the composite material compromises the integrity of the composite resin-tooth interface, and can lead to the gap formation. Adhesive failure results in loss of marginal seal, creating a gap between the tooth and the restoration. This implies a clinically undetectable passage of bacteria, fluids, molecules and/or ions from 
one structure to the other, known as marginal leakage. Thus, microleakage associated with polymerization shrinkage is a major drawback of resin composites, since the resulting shrinkage stress can cause microgap formation at the resin-enamel interface. Indeed, microleakage is one of the most cited reasons for failure of composite resin restorations (Dickinson \& Leinfelder, 1993; Davidson \& Feilzer, 1997; Santhosh et al., 2008). The shrinkage stresses generated during polymerization can lead to loss of marginal adaptation, resulting in adhesion failure and microgap formation. Moreover, polymerization shrinkage can cause cohesive failure, with loss of dentin and inadequate sealing of the dentinal tubules. Thus, microleakage resulting from polymerization shrinkage can lead to secondary caries, postoperative sensitivity, marginal staining, and, if left untreated, can advance to pulpal pathology. The stress generated during polymerization of the material is influenced by several factors associated with the material, restoration technique, cavity preparation, and their respective interactions. Polymerization shrinkage is intrinsic to the use of composite resins; although it cannot be avoided, it can be decreased or counterbalanced. In this regard, a number of strategies have been proposed, such as the stratified layering technique consisting of placing the restoration gradually by applying the composite in successive layers of no more than $2 \mathrm{~mm}$ (Ferracane, 2011). This process is based on achieving complete polymerization of each increment, with each increment compensating for polymerization shrinkage of the previous increment, by using techniques such as ramp polymerization, decreasing light intensity, lightpolymerization through the tooth tissue, and rebonding the margins of the restoration, among others.

Thus, the importance of achieving a perfect marginal seal is paramount to the success and longevity of a composite filling (Moncada et al., 2008). A number of methods to reduce the occurrence of microleakage at the tooth-restoration interface have been suggested. One of such methods involves applying a thin layer of low viscosity resin containing no filler over the cavosurface margins of the finished restoration (Dickinson \& Leinfelder; Ramos et al., 2002; Erhardt et al., 2002). This type of material penetrates into the structural micro defects and marginal gaps by capillary action, sealing them and thus improving marginal seal (Pérez et al., 2009). In addition, this low viscosity resin containing no filler would fill or repair the pores and structural defects generated during the finishing and polishing processes. Clinical studies have shown that marginal re-bonding techniques significantly improve wear resistance (Prakki et al., 2005; Giachetti et al., 2006) and prolong marginal integrity (Giachetti et al.; Ramos et al.).

Surface sealants are light polymerizable materials containing bisphenol-A glycidyl methacrylate (bis-GMA), urethane dimethacrylate (UDMA), and three-ethylene glycol dimethacrylate (TEGDMA), without filler particles, and characterized by low viscosity and high wettability (Magni et al., 2008; Mousavinasab et al., 2008; Hepdeniz et al., 2016) which enables them to penetrate into the microdefects at the tooth-restoration interface.

Besides these low viscosity materials, commercially available adhesive systems could also be used for rebonding, though their effectiveness in reducing microleakage in composite restorations remains to be determined (Prakki et al.; D'Alpino et al., 2006; Owens \& Johnson, 2006; dos Santos et al., 2008; Silva Santana et al.).

Based on the above, the hypothesis of the present study was that surface sealants and adhesive systems are effective in decreasing marginal microleakage in composite resin restorations.

Overall objective. The aim of the present study was to evaluate and compare the effectiveness of surface sealants and adhesive systems in marginal re-bonding and in decreasing microleakage of Class 1 composite restorations.

Specific objectives. To determine the degree of microleakage based on dye penetration at the toothrestoration interface.

- To compare the performance of the studied materials for marginal re-bonding in class 1 composite resin restorations.

- To determine which material is the most effective in rebonding the tooth-restoration interface.

\section{MATERIAL AND METHOD}

Thirty non-carious upper and lower premolars extracted for orthodontic purposes were stored in distilled water at room temperature until use. Occlusal enamel-dentin cavities were prepared and filled with One Coat Bond SL (LOT, 0164128) and Brilliant New 
Generation (Coltene Whaledent. LOT 0183492), following the manufacturer's instructions, and were appropriately polished.

The samples were then randomly assigned to one of six treatment groups, as shown in Table I.

After finishing and polishing, the specimens in groups II to VI were rinsed thoroughly with water, and air dried. Phosphoric acid $37 \%$ (Eco-Etcht-Ivoclar Vivadent) was then applied on the surface of the composite and the enamel, 1 to $2 \mathrm{~mm}$ beyond the toothrestoration interface, for 15 seconds and dried for 30 seconds. Following, a thin layer of the resins and adhesive sealant systems was applied over the etched restoration and enamel using a brush; the layer was spread gently using air, and was light polymerized for 20 seconds using a halogen light lamp (XL 3000, 3M ESPE.USA) at a light intensity of $540 \mathrm{~mW} / \mathrm{cm}^{2}$. The apexes of the teeth were sealed using an adhesive and composite resin. Two coats of nail varnish were applied to all the outer surfaces of the teeth, except for a $1 \mathrm{~mm}$ margin around the restorations. The samples were then immersed in a $2 \%$ methylene blue solution for 48 hours at a standardized temperature of $37^{\circ} \mathrm{C}$ (Table II). The samples were stored in distilled water at $37 \pm 1^{\circ} \mathrm{C}$ and were thermocycled (1500 cycles between $5^{\circ} \mathrm{C}$ and $55^{\circ} \mathrm{C}$ ). They were rinsed thoroughly under tap water, and ground to the medial plane in a buccal-palatal orientation on rotating silicon-carbide discs of decreasing abrasiveness, for observation under a stereoscopic loupe with 40 to $50 \mathrm{X}$ magnification. The degree of leakage was evaluated by two calibrated researchers, and scored according to the penetration of the dye into the tooth-restoration interface using a 0 to 3 grading scale (Arisu et al., 2009), Grade 0: no dye penetration; Grade 1: mild; limited penetration into the cavosurface margin; Grade 2: moderate; penetration of the dye into the enamel; and Grade 3: extensive; dye penetration reaching the enamel-dentin junction (Table II).

Statistical Analysis: The obtained results were analyzed using the Kruskal-Wallis non parametric test.

Table I. Experimental Materials

\begin{tabular}{lll}
\hline \multicolumn{1}{c}{ Group } & \multicolumn{1}{c}{ Experimental Material } & \multicolumn{1}{c}{ Manufacturer } \\
\hline I & Control: No sealant (C) & 3 M ESPE. Dental Products. USA. LOT. 9XJ \\
II & Adper Single Bond 2 (SB) & Ultradent Products, Inc USA. LOT. 1- 800 - 552 - 5512 \\
III & Perma Seal (PS) & Ivoclar - Vivadent AG. Schaan. Liechtenstein. LOT. L 05315 \\
IV & Heliobond (HE) & Bisco, Inc USA.- LOT 0800013536 \\
V & Biscover LV (BIS) & Biodinámica, Ibipora.PR. Brazil LOT 615/09 \\
VI & bioforty (BIO) &
\end{tabular}

Table II. Degrees of marginal leakage

\begin{tabular}{cl}
\hline Score & Microleakage \\
\hline $\mathbf{0}$ & No dye penetration \\
$\mathbf{1}$ & Mild; dye penetration to the CSM \\
$\mathbf{2}$ & Moderate; dye penetration to the enamel \\
$\mathbf{3}$ & Extensive; dye penetration to the EDJ \\
\hline $\begin{array}{l}\text { Key: SCM: cavosurface margin; EDJ: enamel dentin } \\
\text { junction }\end{array}$
\end{tabular}

\section{RESULTS}

Results of the Kruskal-Wallis non parametric test are shown in Figure 1.

The bar graph shows the percentage and number of samples showing grade 1, 2 and 3 microleakage per group. Significant differences were observed between each of the experimental groups and the control group $(p=0.0167)$, which showed the worst results since all control teeth exhibited some degree of leakage. In addition, the materials used in groups II, III and VI showed similar performance in terms of adequate marginal sealing, given that 80 to $100 \%$ of teeth in these groups exhibited no microleakage. No significant differences in effectiveness were observed among Single Bond, Perma Seal and bioforty. As regards the materials used for surface rebonding, the materials used in groups IV and $\checkmark$ were found to be equally effective, with treated teeth showing moderate microleakage; no significant differences were observed between Heliobond and Biscover LV.

Microphotographs 1, 2, 3, 4, and 5 show dye penetration determinations in a sample from each group; the images corroborate the obtained results. (Figs. 2 - 6) 


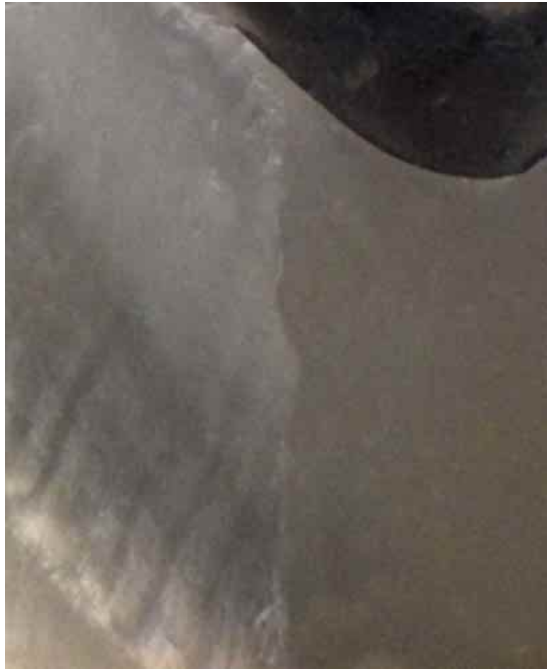

Fig. 1. Percentage and number of samples showing G0, G1, G2 and G3 microleakage per group.

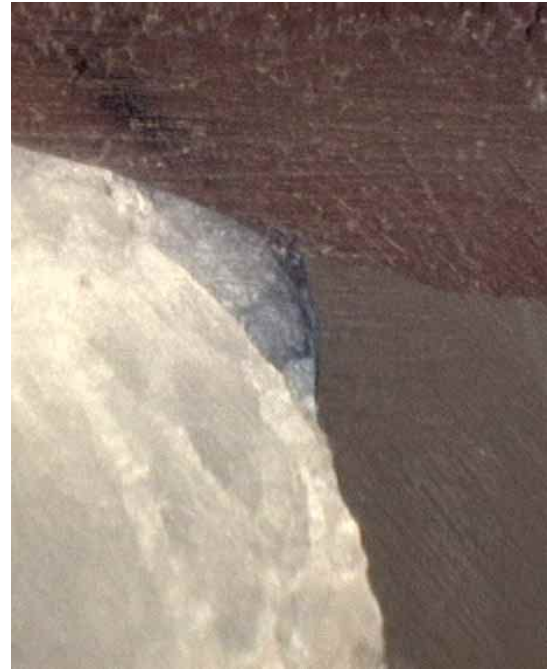

Fig. 2. Photomicrograph of a histological section corresponding to Group III (PS) showing no microleakage; Magnification: $50 \mathrm{X}$.

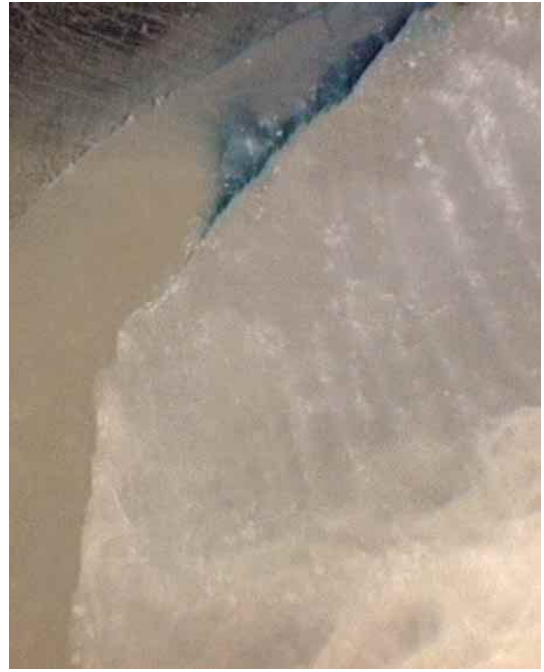

Fig. 3. Photomicrograph of a samples corresponding to Group IV (HE), showing Grade 1 microleakage; Magnification: 50X.

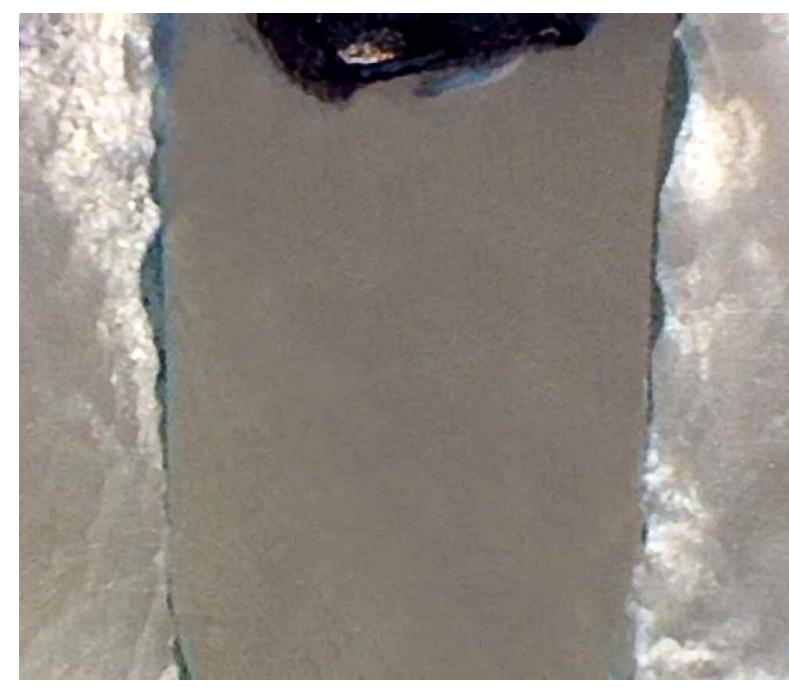

Fig. 4. Photomicrograph of a histological section corresponding to Group V (BIS) showing Grade 1 microleakage; Magnification: $50 \mathrm{X}$.

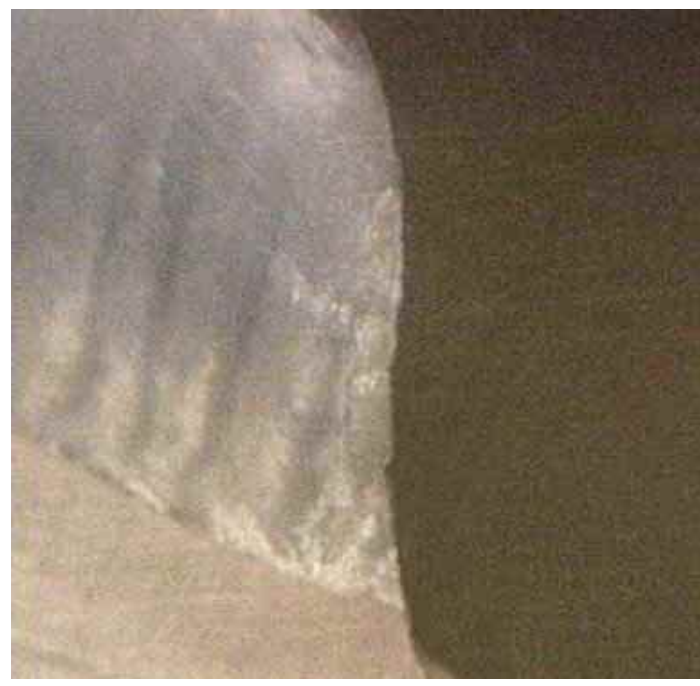

Fig. 5. Photomicrograph of a samples corresponding to the Control Group (I) showing extensive microleakage; Magnification: $50 \mathrm{X}$.

\section{DISCUSSION}

Microleakage due to the deterioration of marginal adaptation is one of the main causes of restoration failure in Restorative Dentistry. An optimal marginal seal is essential to restoration longevity.

Microleakage cannot be detected easily in the clinical setting (Irie \& Suzuki, 2002; Rosin et al., 2002;
Neves et al., 2014). Unless certain subjective symptoms are present, such as white or brown marginal staining, sensitivity to heat or cold, or spontaneous pain, it is difficult to detect microleakage. If it is not detected at an early stage, is not adequately treated, or remains untreated over a long period of time, microleakage can lead to severe caries progression (Neves et al.). 


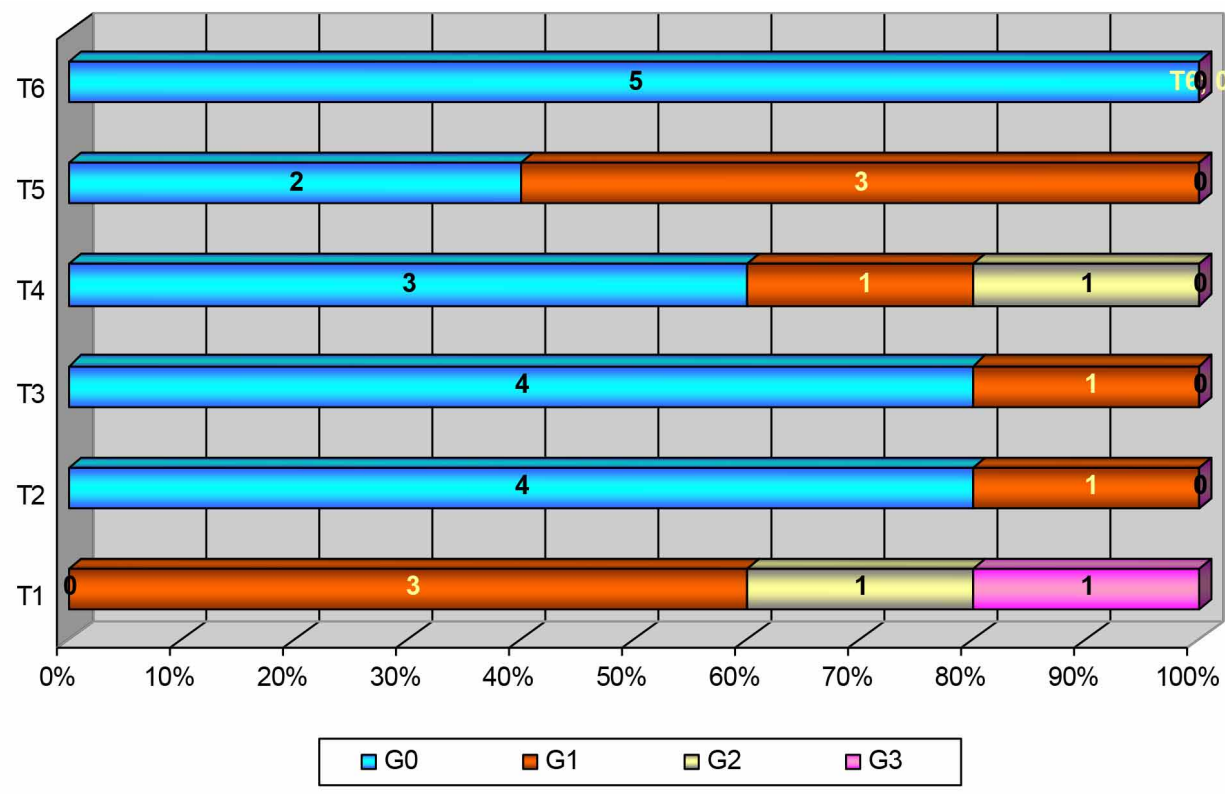

Fig. 6. Photomicrograph of a histological section corresponding to Group II (Adper Single Bond) showing Grade 0 microleakage; Magnification: 50X.

Therefore, the present work evaluated the influence of different surface sealants and adhesive systems on reducing marginal leakage of class 1 composite restorations (el-Din et al., 2002). Our results showed different degrees of microleakage at the toothrestoration interface. Despite the continuing advances in adhesive systems, microleakage continues to be a matter of concern with composite restorations. Microleakage tests are useful methods to evaluate the sealing ability of a material. Dye penetration is the most widely used method, since it is reliable and easy to use. Ramos et al., dos Santos et al. and Sadeghi et al. (2013) showed that the re-bonding technique can substantially minimize microleakage at the margins of composite resin restorations when a low viscosity surface sealant is applied over cavosurface margins of finished restorations (Dickinson \& Leinfelder). These materials penetrate into the structural micro-defects and marginal gaps by capillary action, sealing them and thus improving marginal sealing. In addition, they would fill or repair the pores and structural defects formed during the finishing and polishing processes. These materials are commercially available in a range of monomer combinations, including BisGMa, TEGDMA and UDMA. Nevertheless, in order for surface sealants to be effective, they must have good wettability properties, low contact angle to penetrate into small restoration defects, and a surface tension equal to or lower than the critical surface tension of the restoration/tooth structure (Prakki et al.; Ferracane).

To avoid further costs to both the clinician and patient, the use of a dentin adhesive to fulfil this purpose has been suggested. In the present study, different materials were selected to evaluate how their composition might influence fluidity and penetrability, thus preventing microleakage.

A liquid polishing system (Biscover/Bisco) was recently introduced with the aim to reduce or even eliminate the need for polishing restorations manually. This material is a light polymerizable liquid resin that could also be used as a surface sealant, even though it was not specifically developed for this purpose.

The aim of the present work was to evaluate the performance of different surface sealants, a dentin adhesive, and the liquid polishing system, and their influence on microleakage of composite restorations.

The obtained results showed that etching with $37 \%$ phosphoric acid and subsequent application of a surface sealant or a single-component adhesive (Adper Single Bond/ 3M-ESPE) significantly decreased microleakage as compared to the control samples with no sealant. These observations are in line with findings 
reported by Ramos et at. And Erhardt et al. but are contrary to the report by D'Alpino et al.

Based on the information provided by the manufacturers, most surface sealants are urethane based materials (UDMA) varying in the diluting agent, viscosity, and curing mechanisms, all of which could influence the clinical performance of the various commercially available materials (Ramos et al.). This would explain the better performance of the materials used in groups II (Single Bond), III (Perma Seal) and $\mathrm{VI}$ (Bioforty), and the significant differences compared to groups IV (Heliobond) and V (Biscover LV). Other studies reported in the literature have shown that an etched, clean and dry surface is the ideal environment for a surface sealant to penetrate in the marginal space, and enhance wettability by achieving high surface tension levels. It can therefore be concluded that acid etching has a positive impact on the sealing ability of the material. Moreover, sealants and adhesives can contain filler particles and opaquers that decrease fluidity and increase viscosity of the material, resulting in decreased wettability of the prepared surfaces and inadequate sealing.

In the present study, all the rebonded composite restorations showed varying degrees of microleakage at the tooth-restoration interface. This finding is in agreement with observations reported by Silva Santana et al., D'Alpino et al. and Yang et al. (2016) who concluded that surface sealants vary in their effectiveness in reducing microleakage. Further clinical studies are necessary to determine whether rebonding provides some clinical benefit in terms of restoration longevity and decreasing marginal staining around the restorations.

\section{CONCLUSIONS}

The present results obtained under the experimental conditions described herein would seem to indicate that the effectiveness of rebonding with surface sealants and adhesives in preventing microleakage differs according to the composition and viscosity of the rebonding material.

Applying the rebonding technique could be considered appropriate to reduce microleakage of composite resin restorations, and this effect would seemingly be associated with the characteristics of the material. Therefore, it would seem convenient to apply surface sealants over composite restorations in order to improve marginal integrity and decrease microleakage and wear of the occlusal surface.

URQUÍA, M. C.; BRASCA, N.; GIRARDI, M.; BONNIN, C.; RÍOS, A.; GIRARDI, I.; CHÁVEZ, L. J. \& DELGADO, A. Estudio de la influencia de los sellantes de superficie sobre la microfiltración en restauraciones de composite. Int. J. Odontostomat., 11(4):467-473, 2017.

RESUMEN: La contracción de polimerización de los composites puede generar fuerzas que determinan la formación de microbrechas en la interfase resina-esmalte y filtración marginal. El objetivo de este trabajo fue evaluar la influencia de los sellantes de superficie, en restauraciones de composite, sobre la microfiltración. Se utilizaron 30 premolares superiores e inferiores, libres de caries, donde se realizaron preparaciones oclusales amelodentinarias que fueron obturadas con One Coat Bond SL y Brilliant New Generation (Coletene), siguiendo las indicaciones del fabricante y pulidas adecuadamente. Luego las muestras se distribuyeron aleatoriamente en seis grupos, según los materiales experimentales: Grupo I (Control), Grupo II: Single Bond (3M/ESPE), Grupo III: Perma Seal (Ultradent), Grupo IV: Heliobond (Vivadent), Grupo V: Biscover LV (Bisco), Grupo VI: bioforty (biodinámica). Posteriormente las piezas fueron sometidas a ciclaje térmico por 100 ciclos entre $5^{\circ} \mathrm{C}$ y $55^{\circ} \mathrm{C}$, sumergidas en una solución acuosa de azul de metileno al $2 \%$ durante 48 horas y desgastadas en sentido V-P, hasta el plano medial, para ser observadas con lupa estereoscópica a 40 X. El grado de filtración se evaluó por la penetración del colorante en la interfase diente-restauración en una escala de $\mathrm{O}$ a 3. Los datos obtenidos fueron analizados mediante la muestra no paramétrica de Kruskal-Wallis. Se encontraron diferencias significativas de todos los grupos con respecto al grupo control $(p=0,0167)$, no existiendo significación entre Single Bond, Perma Seal y bioforty ni entre Heliobond y Biscover LV. En restauraciones de composite, sería conveniente la aplicación de sellantes de superficie para mejorar la integridad marginal y disminuir la microfiltración.

PALABRAS CLAVE: microfiltración, sellantes de superficie, composites.

\section{REFERENCES}

Arisu, H. D.; Eliguzeloglu, E.; Uctasli, M. B.; Omurlu, H. \& Turkoz, E. Effect of multiple consecutive adhesive coatings on microleakage of class v cavities. Eur. J. Dent., 3(3):17884, 2009

D’Alpino, P. H.; Pereira, J. C.; Rueggeberg, F. A.; Svizero, N. R.; Miyake, K. \& Pashley, D. H. Efficacy of composite surface sealers in sealing cavosurface marginal gaps. J. Dent., 34(3):252-9, 2006. 
URQUÍA, M. C.; BRASCA, N.; GIRARDI, M.; BONNIN, C.; RÍOS, A.; GIRARDI, I.; CHÁVEZ, L. J. \& DELGADO, A. Influence of surface sealants on microleakage in composite restorations. Int. J. Odontostomat., 11(4):467-473, 2017.

Davidson, C. L. \& Feilzer, A. J. Polymerization shrinkage and polymerization shrinkage stress in polymer-based restoratives. J. Dent., 25(6):435-40, 1997.

Dickinson, G. L. \& Leinfelder, K. F. Assessing the long-term effect of a surface penetrating sealant. J. Am. Dent. Assoc., 124(7):68-72, 1993.

dos Santos, P. H.; Pavan, S.; Assunção, W. G.; Consani, S.; Correr-Sobrinho, L. \& Sinhoreti, M. A. Influence of surface sealants on microleakage of composite resin restorations. J. Dent. Child. (Chic.), 75(1):24-8, 2008.

el-Din, A. K. \& Abd el-Mohsen, M. M. Effect of changing application times on adhesive systems bond strengths. Am. J. Dent., 15(5):321-4, 2002.

Erhardt, M. C.; Magalhães, C. S. \& Serra, M. C. The effect of rebonding on microleakage of class $\mathrm{V}$ aesthetic restorations. Oper. Dent., 27(4):396-402, 2002.

Ferracane, J. L. Resin composite--state of the art. Dent. Mater., 27(1):29-38, 2011.

Giachetti, L.; Scaminaci Russo, D.; Bambi, C. \& Grandini, R. A review of polymerization shrinkage stress: current techniques for posterior direct resin restorations. J. Contemp. Dent. Pract., 7(4):79-88, 2006.

Hepdeniz, O. K.; Temel, U. B.; Ugurlu, M. \& Koskan, O. The effect of surface sealants with different filler content on microleakage of Class $\mathrm{V}$ resin composite restorations. Eur. J. Dent., 10(2):163-9, 2016.

Irie, M. \& Suzuki, K. Effects of delayed polishing on gap formation of cervical restorations. Oper. Dent., 27(1):5965, 2002.

Magni, E.; Zhang, L.; Hickel, R.; Bossù, M.; Polimeni, A. \& Ferrari, M. SEM and microleakage evaluation of the marginal integrity of two types of class $\mathrm{V}$ restorations with or without the use of a light-curable coating material and of polishing. J. Dent., 36(11):885-91, 2008.

May, K. N. Jr.; Swift, E. J. Jr.; Wilder, A. D. Jr. \& Futrell, S. C. Jr. Effect of a surface sealant on microleakage of Class $\mathrm{V}$ restorations. Am. J. Dent., 9(3):133-6, 1996.

Moncada, G.; Fernández, E.; Martín, J.; Arancibia, C.; Mjör, I. A. \& Gordan, V. V. Increasing the longevity of restorations by minimal intervention: a two-year clinical trial. Oper. Dent., 33(3):258-64, 2008.

Mousavinasab, S. M.; Khosravi, K. \& Tayebghasemi, N. Microleakage assessment of class $\mathrm{V}$ composite restorations rebounded with three different methods. Dent. Res. J., 5(1):21-6, 2008.

Neves, A. A.; Jaecques, S.; Van Ende, A.; Cardoso, M. V.; Coutinho, E.; Lührs, A. K.; Zicari, F. \& Van Meerbeek, B. 3D-microleakeage assesment of adhesive interfaces: exploratory findings by $\mu$ CT. Dent. Mater., 30(8):799-807, 2014.

Owens, B. M. \& Johnson, W. W. Effect of new generation surface sealants on the marginal permeability of Class $\mathrm{V}$ resin composite restorations. Oper. Dent., 31(4):481-8, 2006.

Pérez, C. dos R.; Hirata, R. J.; da Silva, A. H.; Sampaio, E. M. \& de Miranda, M. S. Effect of a glaze/composite sealant on the 3-D surface roughness of esthetic restorative materials. Oper. Dent., 34(6):674-80, 2009.
Prakki, A.; Ribeiro, I. W.; Cilli, R. \& Mondelli, R. F. Assessing the tooth-restoration interface wear resistance of two cementation techniques: effect of a surface sealant. Oper. Dent., 30(6):739-46, 2005.

Ramos, R. P.; Chinelatti, M. A.; Chimello, D. T. \& Dibb, R. G. Assessing microleakage in resin composite restorations rebonded with a surface sealant and three low-viscosity resin systems. Quintessence Int., 33(6):450-556, 2002.

Rosin, M.; Urband, A. D.; Gärtner, C.; Bernhardt, O.; Splieth, C. \& Meyer, G. Polimerization shrinkage-strain an microleakeage in dentin-bordered cavities of chemically and light-cures restorative materials. Dent Mater., 18(7):521-8, 2002.

Sadeghi, M.; Davari, A. \& Lynch, C. D. The effect of rebonding using surface sealant or adhesive system on microleakage of class $\mathrm{V}$ resin composite restorations. Dent. Res. J. (Isfahan), 10(5):596-601, 2013.

Santhosh, L.; Bashetty, K. \& Nadig, G. The influence of different composite placement techniques on microleakage in preparations with high C-factor: An in vitro study. J. Conserv. Dent., 11(3):112-6, 2008.

Silva Santana, S. V.; Bombana, A. C.; Flório, F. M. \& Basting, R. T. Effect of surface sealants on marginal microleakage in Class $\mathrm{V}$ resin composite restorations. J. Esthet. Restor. Dent., 21(6):397-404, 2009.

Stein, P. S.; Sullivan, J.; Haubenreich, J. E. \& Osborne, P. B. Composite resin in medicine and dentistry. J. Long Term Eff. Med. Implants, 15(6):641-54, 2005.

Yang, S. Y.; Kwonj, J. S.; Kim, K. N. \& Kim, K. M. Enamel surface with pit and fissure sealants containg $45 \mathrm{~s} 5$ bioactive glass. Dent. Res. J., 95(5):550-7, 2016.

Zimmerli, B.; Strub, M.; Jeger, F.; Stadler, O. \& Lussi, A. Composite materials: composition, properties and clinical applications. A literature review. Schweiz. Monatsschr. Zahnmed., 120(11):972-86, 2010.

Corresponding author:

Dra. Nora Brasca

Profesora Adjunta de Operatoria I B

Facultad de Odontología - UNC

Sub-secretaria de Posgrado - Escuela de Posgrado

Facultad de Odontología - UNC

ARGENTINA

Email: norabrasca43@hotmail.com

Received: 11-08-2017

Accepted: 27-10-2017 